\title{
Endophyte Bacteria Alter Physiological Traits and Promote Growth of Rice (Oryza sativa L.) in Aluminium Toxic and Phosphorus Deficient Acid Inceptisols
}

\author{
Joyashri Das ${ }^{1,3 *}$ (D) , Sabira Sultana ${ }^{1}$ (D) Krishnappa Rangappa² (D), \\ Mohan C. Kalita ${ }^{3}$ (D) and Dwipendra Thakuria ${ }^{1 *}$ (D) \\ ${ }^{1}$ Microbial Ecology Lab, College of Post Graduate Studies, Central Agricultural University, Umiam - 793 103, \\ Meghalaya, India. ${ }^{2}$ Plant Physiology Lab, Division of Crop Production, ICAR Research Complex for NEH Region, \\ Umiam - 793 103, Meghalaya, India. ${ }^{3}$ Department of Biotechnology, Gauhati University, Jalukbari, Guwahati, \\ Assam - 781 014, India.
}

\begin{abstract}
Endophytic bacteria are known to impart biotic and abiotic stress tolerance under stressful environments. More than $\mathbf{7 0} \%$ arable area in North-Eastern Himalaya is occupied by acidic soil. The aim of this research was to test the extent of endurance achieved by suitable. Endophytic bacterial inoculation for enhancing crop fitness and also to quantify the realistic benefits for crop growth and performance with bacterial inoculation grown in acidic soil. To achieve this, the strain $22 \mathrm{WE}$, isolated from the wild rice variety Zizania latifolia, was selected because of its growth promoting properties. 16S rDNA sequence of the isolate confirmed its identification as Serratia nematodiphila. This study assessed whether endophyte inoculation can provide the habitat-fitness benefits to rice crops in acidic soil. Further, Kharif rice (var. CAUR3) plants were inoculated with the endophyte selected strain of Serratia nematodiphila. Endophyte inoculated rice plants had significantly $(\mathrm{P}<0.05)$ higher root surface area, root volume, root and shoot biomass contents than that of uninoculated plants grown under aluminium (Al) toxic and phosphorus $(\mathrm{P})$ nutrient conditions. The DAB staining assay exhibited that endophyte inoculation confers advantage to rice plants in terms of reduced reactive oxygen against Al-induced stress. The interaction effects between endophyte inoculation and Al levels was significant $(P<0.05)$ for the malondialdehyde and cell membrane stability values. The current study showed that toxic effect of an approximate $100 \mathrm{ppm}$ Al incurred under any acid soil can be compensated due to the endophyte inoculation.
\end{abstract}

Keywords: Acid Inceptisols, DAB assay, Endophyte, Lipid peroxidation, Rice, Root architecture

*Correspondence: dasjoyashri60@gmail.com; 9101115399, thakuria.dwipendra@yahoo.co.in; 8787343877

(Received: January 21, 2020; accepted: March 05, 2020)

Citation: Joyashri Das, Sabira Sultana, Krishnappa Rangappa, Mohan C. Kalita and Dwipendra Thakuria, Endophyte Bacteria Alter Physiological Traits and Promote Growth of Rice (Oryza sativa L.) in Aluminium Toxic and Phosphorus Deficient acid Inceptisols, J. Pure Appl. Microbiol., 2020; 14(1):627-639. https://doi.org/10.22207/JPAM.14.1.65

(C) The Author(s) 2020. Open Access. This article is distributed under the terms of the Creative Commons Attribution 4.0 International License which permits unrestricted use, sharing, distribution, and reproduction in any medium, provided you give appropriate credit to the original author(s) and the source, provide a link to the Creative Commons license, and indicate if changes were made. 


\section{INTRODUCTION}

Acid soils constitute approximately $40-$ $50 \%$ of the world's arable land (Kochain et al., 2005) and in India about 33\% of the cultivated land (Mandal., 1997). A large portion of extremely acidic soil around $65 \%$ is part of the North Eastern (NE) region of India (Sharma and Singh., 2002). Rice is the principal food grain crop of the people of NE India, occupying 3.51 million hectares which accounts for more than $80 \%$ of the total cultivated region. The total rice production of NE region is much low (Roy et al., 2015). Al toxicity is a major threat for production of crops on acid soils (Silva., 2012). Earth's crust has abundance of Al and at soil $\mathrm{pH}$ below 5.0, mineral Al solubilises into trivalent $\mathrm{Al}^{3+}$ which has toxic effects on plants (Panda et al., 2009). Root growth is inhibited by phytotoxic$\mathrm{Al}\left(\mathrm{Al}^{3+}\right)$ and consequently hinders the uptake of water and nutrient in plants (Rahman et al., 2018). Adoption of altered root architecture due to varied plant hormone synthesis, generation of higher reactive oxygen species, higher peroxidation of fatty acid and increased osmolytes like proline in rice plants grown under aluminium toxicity attributes to aluminium resistance (Guo et al., 2012). To increase soil $\mathrm{pH}$ and reduce $\mathrm{Al}$ toxicity farmers are advised to apply lime but due to the buffering capacity of soil the effect of such amendments are not much beneficial (Zheng and Yang., 2005). On the other hand, P is easily fixed by $\mathrm{Al}$ and Fe present in acidic soil making $\mathrm{P}$ unavailable for root uptake (Adnan et al., 2018). Thus, $P$ deficiency is regarded as another significant constraint in acidic soil for crop cultivation. Although $\mathrm{P}$ fertilizer is applied to increase crop production it is expensive and has detrimental environmental affects.

In this context beneficial bacteria (both rhizospheric bacteria and endophytes) can possibly improve plant development in a wide scope of climatic and edaphic stress conditions (Glick., 2012). Beneficial bacteria (rhizobacteria and endophyte) can colonize the surface or inside various plant tissue parts and rhizosphere zone, where they either exhibit functions which benefits the host or live commensally. Soil is a complex microbial habitat where plant seeds typically fall and germinate when they receive environmental signals. As seeds begin to germinate, seed endophytes form part of the seedling bacterial community and colonize various plant tissues as the plant begins to grow. Hence endophyte bacteria can be characterised as those bacteria that colonize inside tissues of the plant and usually results to be beneficial to the host. (Hardoim et al., 2016). There is considerable evidence that endophytes are involved in enhanced nutrient acquisition, control plant disease, produce plant growth hormone and provide habitat-adaptive fitness to the host plant (Redman et al., 2011; Mitter et al, 2013; Prashar et al., 2014). Endophytes isolated from various plants parts produce indole acetic acid, cytokinins, gibberellins, siderophores, supply essential vitamins to host plant and solubilise insoluble phosphates which enhances plant growth (Etminani and Harighi; 2018, Jha et al., 2012). Inoculating plants with bacteria having plant growth promoting properties to enhance plant growth and productivity is seemingly useful practice adopted. The exploitation of endophytes in mitigating environmental stress on plants has been acquiring new intrigue (Ryan et al., 2007; Bulgarelli et al., 2013) and it is now well established that endophytes can improve growth of plants under various abiotic stress conditions (Khare et al., 2018).

So, it was hypothesized that the habitatfitness of rice crop in Al toxic and $P$ deficient acid soils is independent of endophyte colonization benefits. In order to test our hypothesis we examined the influence of endophyte inoculation on root morphology and a few important physiological stress indicators of rice plant (var CAUR3) grown along a toxicity gradient of $\mathrm{Al}$ in an acid Inceptisols. We also studied the interaction of endophyte on stress physiology, growth and development of rice in a microcosm set-up which received a gradient of $\mathrm{P}$ doses.

\section{MATERIALS AND METHODS \\ Reference Strain}

Serratia nematodiphila (22WE) isolated from the roots (surface sterilized) of wild rice variety Zizania latifolia, collected from the natural habitat of North-East India was the reference strain used in our study. The endophyte was isolated in nutrient agar medium at $30^{\circ} \mathrm{C}$.

\section{Genetic characterization of the strain}

The endophyte was identified by $16 \mathrm{~S}$ rDNA gene sequences. Lysozyme method as 
depicted by Sultana et al., 2019 was used to extract the genomic DNA of the isolate. The pure culture colonies of the endophyte were incubated for 24 hrs in $5 \mathrm{ml}$ Luria Bertani (LB) broth at $30^{\circ} \mathrm{C}$ and shaking speed of $150 \mathrm{rpm}$. Two milliliter aliquots from this broth were centrifuged. The cell pellet of the culture isolates obtained after centrifugation was subjected to lysis by addition of $10 \mu$ lysozyme $(1 \mathrm{mg} / \mathrm{ml}$, Hi Media, India) followed by addition of $90 \mu l$ sterile water. The sample was then incubated for 30 minutes and 5 minutes at $30^{\circ} \mathrm{C}$ and $95^{\circ} \mathrm{C}$ respectively. For the $\mathrm{PCR}$ amplification genomic DNA in the supernantant was used. 16S rDNA of the endophyte genomic DNA was amplified by using universal bacterial specific primers:-

27F (5-AGAGTTTGATCCTGGTCAG-3) 1492R (5-GGTTACCTTGTTACGACTT-3)

(Lane et al., 1991).

Amplification was done in a Gradient Master Cycler 5331 (Eppendorf Make, Germany) using standard PCR conditions and PCR mixtures (Dey et al., 2018). GenElute PCR clean-up kit (Sigma-Aldrich, USA) was used for the purification of amplified products and sequenced by First BASE Laboratories, Malaysia. The $16 \mathrm{~S}$ rRNA sequence obtained was looked for similarity in the GenBank reference genome database using BLASTn. Eztaxon website was used to confirm the strain designated. The sequences of the isolate are available in GenBank with accession number. The GenBank accession number of the strain is MH014960.

Surface sterilization and inoculation of seeds

The inoculum was prepared by incubation of Serratia nematodiphila in LB broth for $24 \mathrm{~h}$. The pellet of the bacterial suspensions was obtained by centrifugation at $2,400 \mathrm{~g}$ for $12 \mathrm{mins}$ at $25^{\circ} \mathrm{C}$. The pellet was suspended in sterile distilled water and the cell density of the bacterial suspension was adjusted to $10^{8}$ cells $\mathrm{mL}^{-1}$ by OD measurement at $600 \mathrm{~nm}$. For surface sterilization of the seeds of the CAUR3 variety, seeds were first immersed in $70 \%$ ethanol for 1 min followed by immersion in $2 \%$ sodium hypochlorite for 5 mins and then finally in $70 \%$ ethanol for 30 secs. The seeds were then rinsed in sterile water four times and then immersed in bacterial suspension of $10 \times 10^{8}$ cells $\mathrm{mL}^{-1}$ for $2 \mathrm{hrs}$. After that the inoculated seeds were kept on sterile tissue paper for about 45 mins to dry and allowed to germinate for 2 days.
Plant growth promoting (PGP) properties of the endophyte

\section{Estimation of IAA}

Free IAA-like substances, was determined according to Thakuria et al., (2004). Nutrient Broth amended with $0.2 \%$ L-tryptophan was prepared where the endophyte suspension of the pure isolate $(100 \mu \mathrm{l})$ was allowed to grow for $48 \mathrm{hrs}$ by incubation at the temperatute of $32^{\circ} \mathrm{C}$ and shaking at the speed of $100 \mathrm{rpm} .1 \mathrm{ml}$ of the supernatant obtained after centrifugation of the broth at $10,000 \mathrm{~g}$ for $12 \mathrm{mins}$ at $4^{\circ} \mathrm{C}$ was mixed with $4 \mathrm{ml}$ Salkowski's reagent $\left(0.5 \mathrm{M}\right.$ ferric chloride $\left(\mathrm{FeCl}_{3}\right.$ and $35 \%$ perchloric acid $\left(\mathrm{HClO}_{4}\right)$. After 20 mins free IAA-like substances was determined using spectrophotometer by observing the absorbance at $530 \mathrm{~nm}$ and from the standard curve prepared using different concentration of serially diluted IAA (Sigma-Aldrich, USA).

\section{Cellulolytic Activity}

The cellulose degrading effectiveness of the endophyte strain was determined by incubating the strain in $\mathrm{CMC}$ agar plates for a period of $48 \mathrm{hrs}$ (Verma et al., 2001). The plates were stained with $1 \%$ Congo Red and counter stained with 1 molar $\mathrm{NaCl}$. The zone formed around the colony indicates the cellulolytic activity of the strain.

\section{Mineral phosphate solubilisation}

Pikovskaya's medium was used for the determination of the solubilization of phosphate by the endophyte. The broth was inoculated with the bacterium and incubated at $30^{\circ} \mathrm{C}$ for 72 $\mathrm{h}$ and shaking with the speed of $150 \mathrm{rpm}$. The clear supernatant of the culture obtained after centrifugation (4000 rpm for $1 \mathrm{~min}$ ) was used for the estimation of the soluble phosphorus by stannous chloride blue colour method as described by Brayet and Kurtz (1945).

Determination of 1-aminocyclopropane-1carboxylate (ACC) deminase activity

To determine ACC deaminase activity endophyte isolate was grown in DF (Dworking and Foster) broth having a concentration of 0.5 $\mathrm{mol}^{-1}$ ACC following Penrose and Glick., (2003) method. Enzymatic cleavage of ACC produced $\alpha$-ketobutyrate which was determined from the standard curve of a series of known concentration (between 0.1 and $1.0 \mathrm{~mol}$ ) of $\alpha$-ketobutyrate 
(Sigma-Aldrich, USA) colorimetrically using a spectrophotometer (OD $540 \mathrm{~nm}$ ). ACC deaminase activity was determined in micromoles of $\alpha-$ ketobutyrate per milligram of protein every hour. Microcosm experiments

Two microcosm experiments, with acid Inceptisols (pH 4.80; soil organic carbon $1.67 \%$; exchangeable acidity, Al and calcium plus magnesium $0.98,0.3$ and 0.7 meq per $100 \mathrm{~g}$ soil and soil available $\mathrm{P}-3.84 \mathrm{mg} \mathrm{kg}^{-1}$ respectively) was taken in pot culture filled with air dried sieved $(2 \mathrm{~mm})$ and sterilized soil. Pot diameter was $30 \mathrm{~cm}$ and bulk density maintained at $1.36 \mathrm{~g} \mathrm{cc}^{-1}$. Four Al treatments (control, 100, 200 and 300 ppm Al kg-1 soil as $\mathrm{AlCl}_{3}$ ) under two conditions i.e. with and without endophyte inoculation were imposed in one microcosm Four levels of $\mathrm{P}$ as fertilizer treatment (control, $30 \mathrm{~kg} / \mathrm{ha}, 60 \mathrm{kh} / \mathrm{ha} /, 90 \mathrm{~kg} / \mathrm{ha}$ soil as $\mathrm{KH}_{2} \mathrm{PO}_{4}$ ) under the two conditions i.e. with and without endophyte inoculation in another microcosm were imposed.

Each treatment contained 6 replicate pots. Endophyte treated and untreated seedlings of the Kharif rice (var. CAUR3) were transplanted in pot soils according to treatments. In each pot, three plants of rice, of the CAUR3 variety were maintained throughout the period of the experiment. The important morphological and physiological characters sensitive to Al toxicity and the impact of the endophyte were assessed 35 days after transplantation (DAT). Similarly morphological and physiological characters and the impact of endophyte on the plants grown under $\mathrm{P}$ nutrition condition were also assessed after 35 days DAT. For each parameter, influence of factors (with and without endophyte or Al levels and with and without endophyte or P levels) and interactions between endophyte and Al levels and interactions between endophyte and $P$ levels were determined by 2-way factorial CRD using SPSS v. 21.0.

\section{Determination of Root characteristics}

Representative plant samples were collected from each pot under different treatments at active growth stage (35DAT) of rice plant for determination of important root morphological parameters such as root volume (RV), root length $(R L)$, root surface area (RSA) and root diameter (RD) which were determined by using root scanner (EPSON PERFECTION V700 PHOTO). The interpretation of the scanned image was made by professional and user friendly WinRHIZO software. It is a non-statistical method used for measuring different root parameters.

\section{Estimation of root and shoot biomass}

Roots and shoots were collected and their fresh weight was determined in a precision electronic balance and then died in a hot air oven $\left(60^{\circ} \mathrm{C}\right)$ to a constant weight. Dry root and shoot weight was measured and expressed in gram per plant.

Evaluation of stress responsive physiological traits

Representative plant samples were collected at 35 DAT from each pot under different Al treatments for determination of important and key aluminium stress responsive physiological traits viz. chlorophyll content (Chl a, b, carotenoid), cell membrane integrity, DAB staining and lipid peroxidation. The same physiological traits were also assayed for the rice plants grown in different $\mathrm{P}$ levels.

\section{Determination of leaf chlorophyll content}

Around $0.5 \mathrm{~g}$ leaves were taken for the estimation of leaf pigments (chlorophyll-a, chlorophyll-b and carotenoids). Fresh leaves were homogenized using acetone (80\%). The supernatant obtained after centrifugation of the homogenized leaf samples were taken in a $100 \mathrm{ml}$ volumetric flask. After adjusting the supernatant in the volumetric flask to $100 \mathrm{ml}$ with $80 \%$ acetone leaf pigments were analyzed calorimetrically. The chlorophyll pigments were expressed in $\mathrm{mg} / \mathrm{g}$ tissue (Nayek et al., 2014).

Chlorophyll a $\left(C_{a}\right)=[12.7(A 663)-2.69(A 645)]$ $\mathrm{X}(\mathrm{V} / 1000) \mathrm{X}(1 / \mathrm{W})$

Chlorophyll b $\left(\mathrm{C}_{\mathrm{b}}\right)=[22.9(\mathrm{~A} 645)-4.68(\mathrm{A663})]$ $\mathrm{X}(\mathrm{V} / 1000) \mathrm{x}(1 / \mathrm{W})$

Carotenoids $=\left(100 \mathrm{~A}_{470}-1.82 \mathrm{C}_{\mathrm{a}}-85.02 \mathrm{C}_{\mathrm{b}}\right) / 198$

Where,

$A=$ Absorbance measured at the specific wave lengths

$\mathrm{V}=$ Final volume of chlorophyll extracted in acetone (80\%)

$\mathrm{W}=$ Weight of fresh tissues

\section{Cell membrane integrity}

The cell membrane integrity of fresh leaves of the rice plants (35 DAT) was analyzed by Sullivan's method (Sullivan and Ross, 1979). Finely cut leaf pieces weighing $0.5 \mathrm{~g}$ were immersed in 
$50 \mathrm{ml}$ of deionised water and incubated under laboratory conditions for $3 \mathrm{~h}$. At the end of $3 \mathrm{~h}$, initial electrical conductivity $\left(C_{1}\right)$ was measured using conductivity meter (Elico co.). Then the beaker containing deionized water with leaf pieces was allowed to boil for around 30 mins and the final electrical conductivity $\left(C_{2}\right)$ was estimated. Cell membrane integrity was computed and expressed as follows:

$$
\text { CMI }(\%)=\left[1-\left(C_{1} / C_{2}\right)\right] \times 100
$$

\section{Measurement of melondialdehyde accumulation by TBARS assay}

The melondialdehyde was determined by the reaction described by Yagi (1987). Leaf tissues were homogenized in trichloroacetic acid and centrifuged. About $1 \mathrm{ml}$ of solution containing trichloro acetic -acid and thiobarbituric acid was added to $0.5 \mathrm{ml}$ of supernatant and centrifuged. The supernatant was taken and its absorbance was measured using spectrophotometer at 532 $\mathrm{nm}$. Aborbance was further measured at $600 \mathrm{~nm}$ to correct non specific turbity by subtracting the absorbance value at $600 \mathrm{mn}$ from the absorbance value at $532 \mathrm{~nm}$.

\section{DAB staining assay}

To detect hydrogen peroxide $\left(\mathrm{H}_{2} \mathrm{O}_{2}\right)$ produced on the leaves due to stress imposition, DAB (3, 3'-diaminobenzidine) staining assay was performed. DAB is oxidized by $\mathrm{H}_{2} \mathrm{O}_{2}$ and generate brown precipitate product (Christensen et al., 1997).

\section{RESULTS AND DISCUSSION}

Roots usually suffer greater exposure to Al stress than shoots. In the present investigation, detailed analysis of root morphological characters, RL RSA, RV and RD with the range of Al concentrations 100ppm 200ppm and 300ppm $\mathrm{kg}^{-1}$ soil showed that there is a decrease in $\mathrm{RL}, \mathrm{RV}$, RSA while RD showed an increase in both treated and untreated plants and these values clearly corroborated with the root architecture depicted in the (Fig. 1. and Fig. 2). But in the endophyte inoculated rice plants there was a significant (0.05) increase in the RSA, RV and RL and decrease in the RD compared to that of uninoculated plants. It was further shown that high aluminium toxicity (Al concentrate of $300 \mathrm{ppm} \mathrm{kg}^{-1}$ soil) had extremely

Table. 1 Plant growth promoting activities Serratia nematophila

\begin{tabular}{lcccc}
\hline $\begin{array}{l}\text { Cellulase Activity zone } \\
\text { diameter in } \mathrm{mm}\end{array}$ & $\begin{array}{c}\text { P-Solubilization } \\
\mathrm{Ca}_{3}(\mathrm{PO} 4)_{4} \\
\left(\mu \mathrm{gml}^{-1} \mathrm{~h}^{-1}\right)\end{array}$ & $\begin{array}{c}\text { Na-Phytate } \\
\left(\mu \mathrm{gml}^{-1} \mathrm{~h}^{-1}\right)\end{array}$ & $\begin{array}{c}\text { ACC Deaminase } \\
\left(\mu \mathrm{gml}^{-1} \mathrm{~h}^{-1}\right)\end{array}$ & $\begin{array}{c}\text { IAA like } \\
\text { substances } \\
\left(\mu \mathrm{gml}^{-1} \mathrm{~h}^{-1}\right)\end{array}$ \\
\hline 18 & 169.5 & 2.97 & 51.3 & 623.0 \\
\hline
\end{tabular}
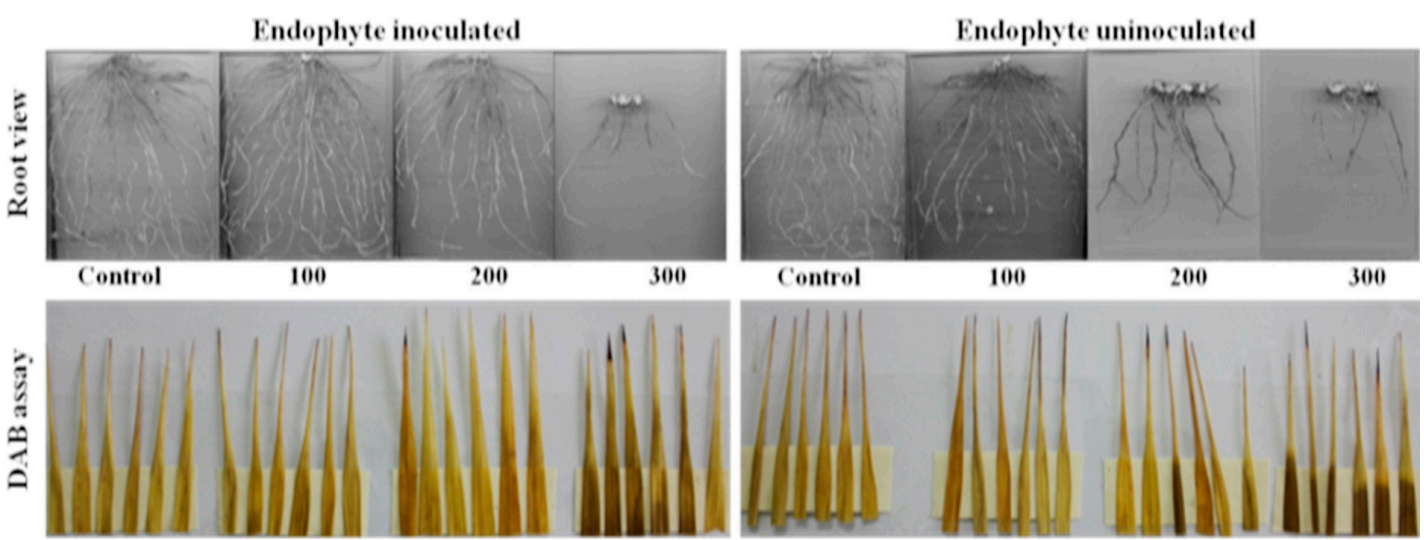

Fig.1. Influence of endophyte colonization and Al levels on root morphological features and $\mathrm{H}_{2} \mathrm{O}_{2}$ activity in fully expanded $3^{\text {rd }}$ leaf determined by DAB assay at 35 DAT of Kharif (CAUR3) grown in an acid inceptisols. 
toxic affect on the rice roots which caused drastic reduction in their growth for both endophyte inoculated and uninoculated plants.

$P$ deficiency can result in the modification of root architecture. In beans and Arabidopsis $P$ deficiency resulted in the decrease of primary root system but increase in the growth of lateral roots while in maize there was reduction in lateral root elongation (Lynch and Brown, 2001, Ticconi et al., 2004). In our study there was also signinificant difference $(P<0.05)$ in the RL, and RV between the inoculated and uninoculated plants. The RSA, $R V$ and RD was highest in P dose $60 \mathrm{~kg} / \mathrm{ha}$ and $\mathrm{RL}$ highest in the plants under under control in both inoculated and uninoculated plants. High dose of
$P$ had negative effect on the root morphological features. RSA, RV and RD was greater in endophyte inoculated plants than the uninoculated plants in all the $\mathrm{P}$ doses and root length lesser in the inoculated plants. (Fig. 3 and Fig. 4).

Al-toxicity causes oxidative stress which results in the alteration of cell wall properties, is a well established phenomenon (Yamamoto et al., 2001). Al can act as catalyst in the production of reactive oxygen species (ROS) which is known to oxidize various cellular units (lipids, proteins, enzymes, and nucleic acids) which causes cell death. The final product of lipid peroxidation, malondialdehyde (MDA) is an indicator of the degree of membrane peroxidation (Wu et al.,
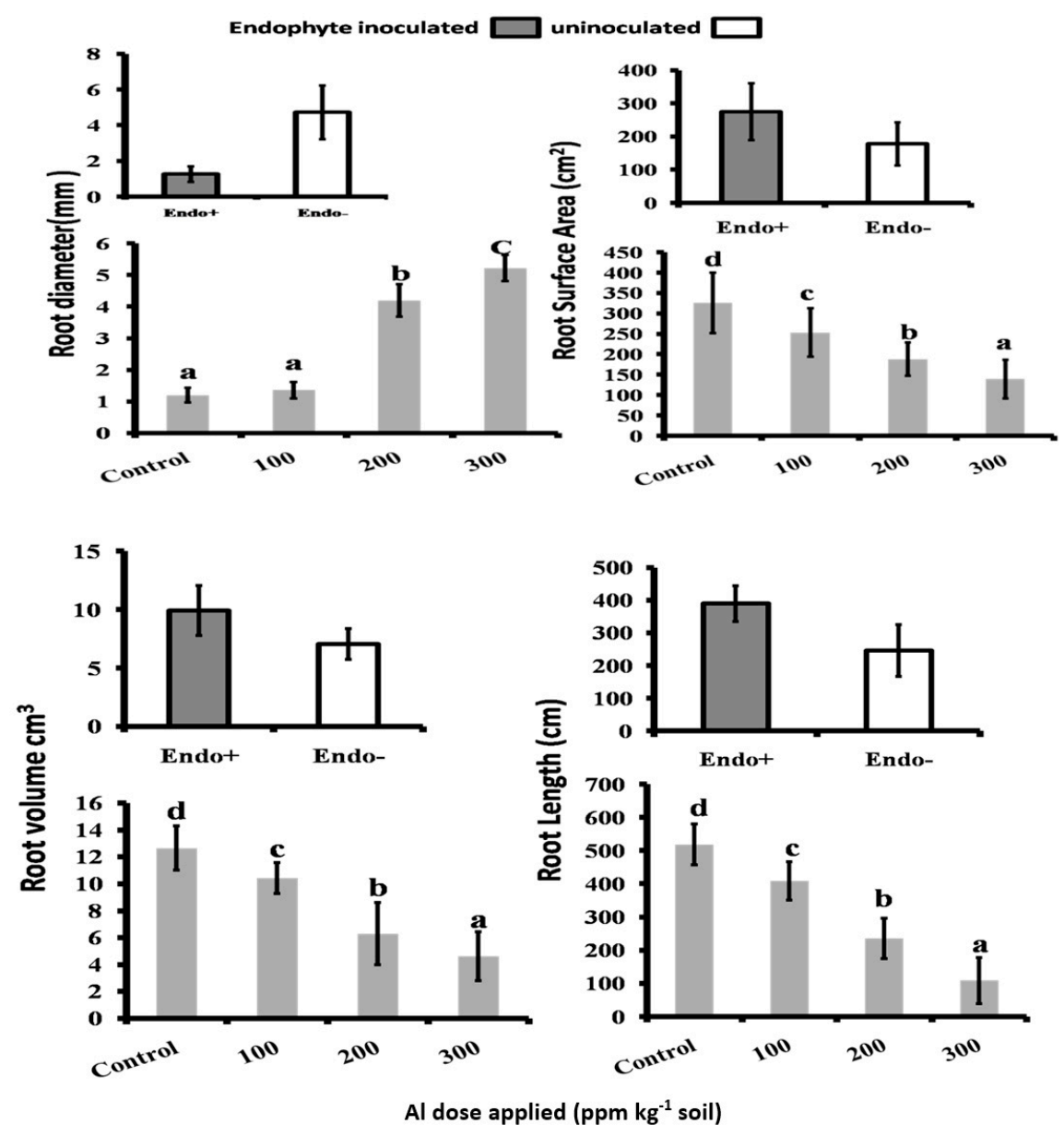

Fig. 2. Root morphological features: Root Diameter (RD), Root Surface Area (RSA), Root Volume (RV) and Root Lenght (RL) of the rice crop(CAUR3 var) grown under different Al-levels and with and without endophyte inoculation. Statististical Analysis was performed by Two Way ANOVA followed by Turkey's post hoc comparision with three replications using SPSS v.21 (SPSS Inc., Chicago, IL, USA). 
2014). In our study MDA content increased with increasing $\mathrm{Al}$ concentration in both endophyte inoculated and uninoculated plants. Plants grown under Al concentration 300 ppm kg-1 soil showed highest MDA content and there was not much difference in the MDA content of the plants grown under $\mathrm{Al}$ concentration $300 \mathrm{ppm} \mathrm{kg}{ }^{-1}$ soil for both endophyte inoculated and uninoculated. However endophyte inoculated plants showed modification in the amount of lipid peroxidation at control, 100ppm, 200ppm levels of Al and there was significantly $(P<0.05)$ lesser amount of MDA in endophyte inoculated plants than uninoculated plants (Table 2).

It is established that plants adopt different mechanisms to circumvent the harmful effects of low $\mathrm{P}$ levels in soil. $\mathrm{P}$ deficiency in plants can cause photo-oxidative stress which is known to cause an increase in ROS production which can damage lipids, proteins and nucleic acids in chloroplast. (Hernandez and Bosh., 2015).We studied the MDA content in the plants grown under different $P$ doses. Our results indicated that the MDA content in the control was highest for both the inoculated and uninoculated plants and lowest in the plant grown under $P$ dose $60 \mathrm{~kg} /$ ha soil (Table 3 ). MDA content of endophyte inoculated and uninoculated plants showed no significant difference.

$\mathrm{H}_{2} \mathrm{O}_{2}$ is a typical ROS which is generated in the cells under normal as well as under stress conditions (Sharma et al., 2012). DAB staining assay used to visualize the $\mathrm{H}_{2} \mathrm{O}_{2}$ in the leaves showed that with the increasing Al concentration the $D A B$ staining enhanced as shown in Fig. 1.
But the extent of $\mathrm{H}_{2} \mathrm{O}_{2}$ production in leaves of endophyte inoculated plants was much lesser than that of uninoculated plants in all Al levels (Fig. 1) except at $300 \mathrm{ppm} \mathrm{kg}{ }^{-1}$ soil concentration of $\mathrm{Al}$, the leaves of both endophyte inoculated and uninoculated plants could be not be visually distinguished by DAB staining.

The $\mathrm{H}_{2} \mathrm{O}_{2}$ production in the endophyte uninoculated plants in the control was more in the control than the inoculated plants (Fig. 3) in case of the $P$ treated plants. At $P$ doses $30 \mathrm{~kg} /$ ha, $60 \mathrm{~kg} / \mathrm{ha}$ and $90 \mathrm{~kg} / \mathrm{ha}$ soil DAB assay could not show any visual difference among the leaves of both inoculated and uninoculated rice plants (Fig. 3).

It has been reported that abiotic stress damage selective permeability of cell membrane and thus the cell cannot mantain its internal composition (Bajji et al., 2002). CMS (Cell Membrane Stability) study which measures the percentage cell membrane leakage showed that with increasing $\mathrm{Al}$ concentration percentage leakage increased for both the endophyte inoculated and uninoculated plants (Table.2.) The CMS values was significantly lesser $(P<0.05)$ in endophyte inoculated plants than the uninoculated plants (Table 2).

Similarly the CMS value in the inoculated plants grown under the different $P$ doses was significantly less than the uninoculated plants (Table.3). The CMS value was lowest in the plants grown under $60 \mathrm{~kg} / \mathrm{ha}$ followed be $30 \mathrm{~kg} / \mathrm{ha}$, $90 \mathrm{~kg} /$ ha soil and control in both inoculated and uninoculated plants.

\section{Endophyte inoculated}

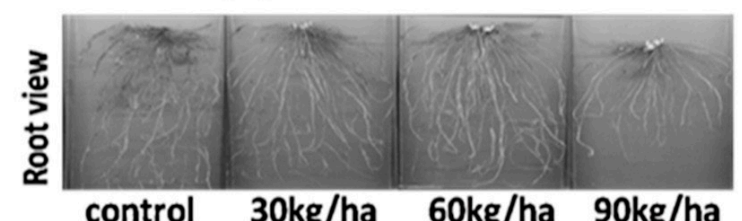

\section{Endophyte uninoculated}

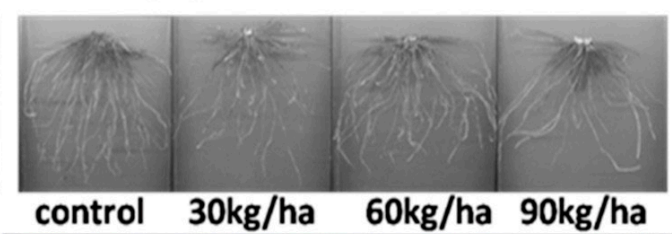

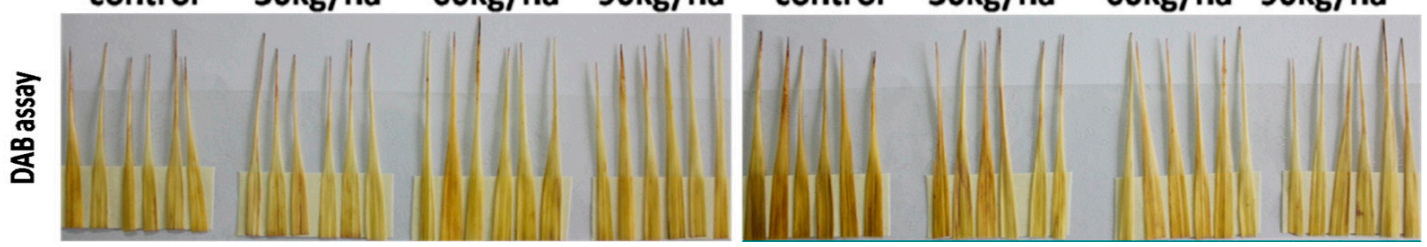

Fig.3. Influence of endophyte inoculation and $P$ levels on root morphological features and $\mathrm{H}_{2} \mathrm{O}_{2}$ activity in fully expanded $3^{\text {rd }}$ leaf tips determined by DAB assay at 35 DAT of Kharif rice (CAUR3) grown in an acid Inceptisols 
It is documented that Al stress can result in the decrease of photosynthetic rate in plants which leads to chlorosis and necrosis of leaves (Thornton et al., 1986). In our study tested chlorophyll content, both chlorophyll $a$ and $b$ decreased with increasing aluminium concentration. The endophyte inoculated plants produced higher chlorophyll a and b content as shown in Table. 2. Carotenoid is another leaf pigment which aid in the light absorbtion for photosynthesis and also protects chlorophyll from any photo damage. (Armstrong and Hearst,
1996). Carotenoid has also been reported to have antioxidant properties (Stahl and Sies, 2003). In our study there was significant $(P<0.05)$ increase in the carotenoid content of uninoculated plants than the inoculated plants.

$P$ deficiency has detrimental effect on photosynthetic characteristics in rice as reported by Xu et al., 2007. We studied the chla, chlb and carotenoid in the leaves grown under the different $P$ levels for both the endophyte inoculated and uninoculated rice plants. Chla content was significantly different among the inoculated and

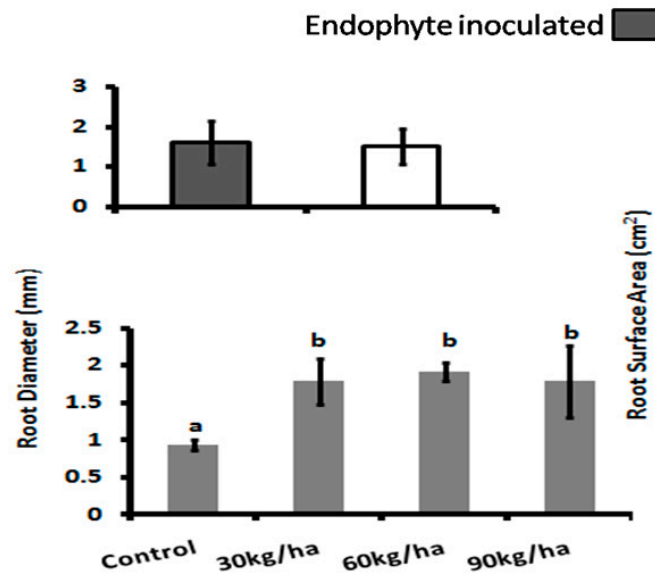

uninoculated
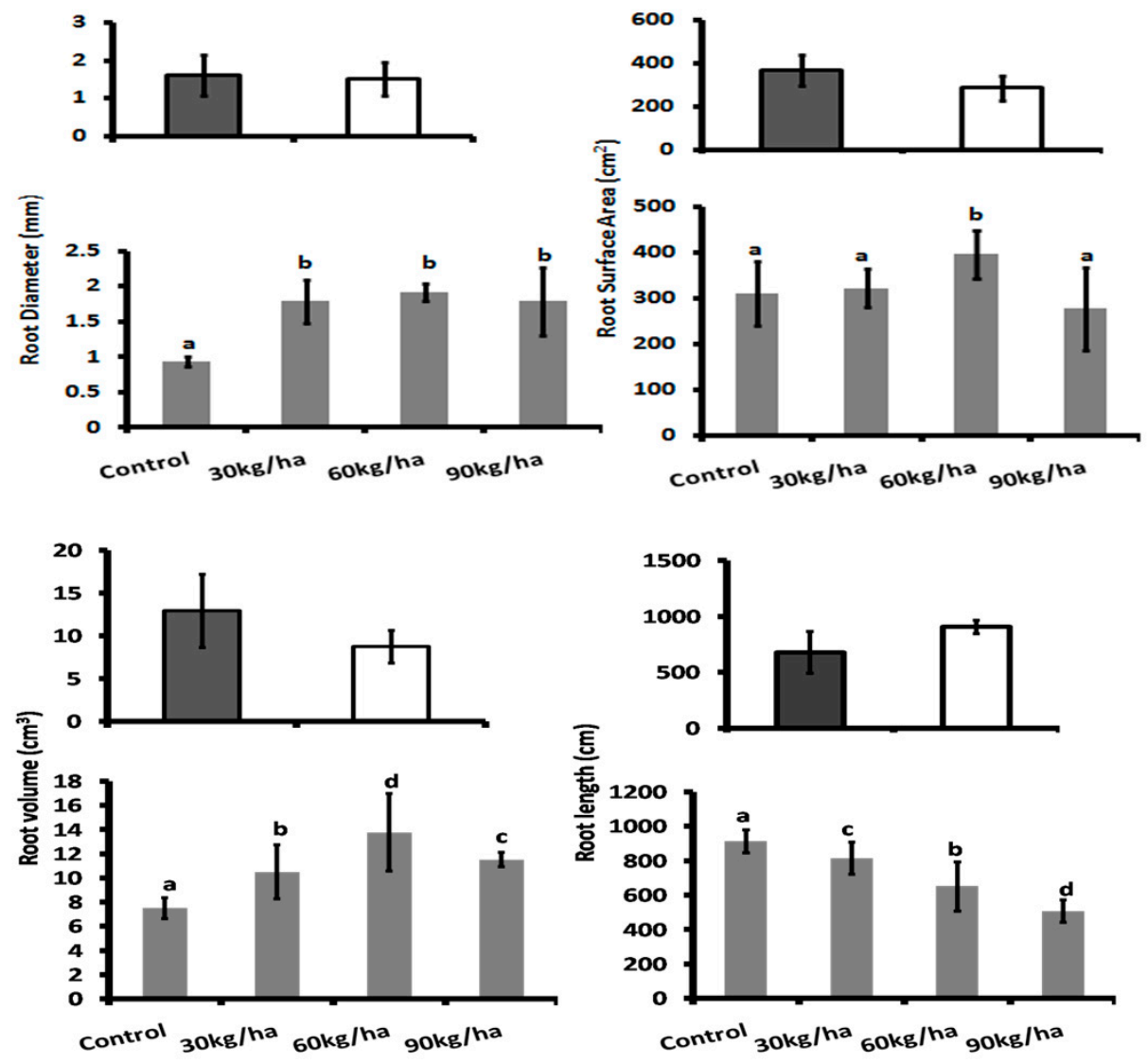

P dose applied (kg/ha soil)

Fig. 4: Root morphological features: Root Diameter (RD) Root Surface Area (RSA), Root Volume (RV) and Root Length $(\mathrm{RL})$ of the rice crop (CAUR3 var) grown under different P-doses and with and without inoculation. Statististical Analysis was performed by Two Way ANOVA followed by Turkey's post hoc comparision with three replications using SPSS v.21 (SPSS Inc., Chicago, IL, USA). 


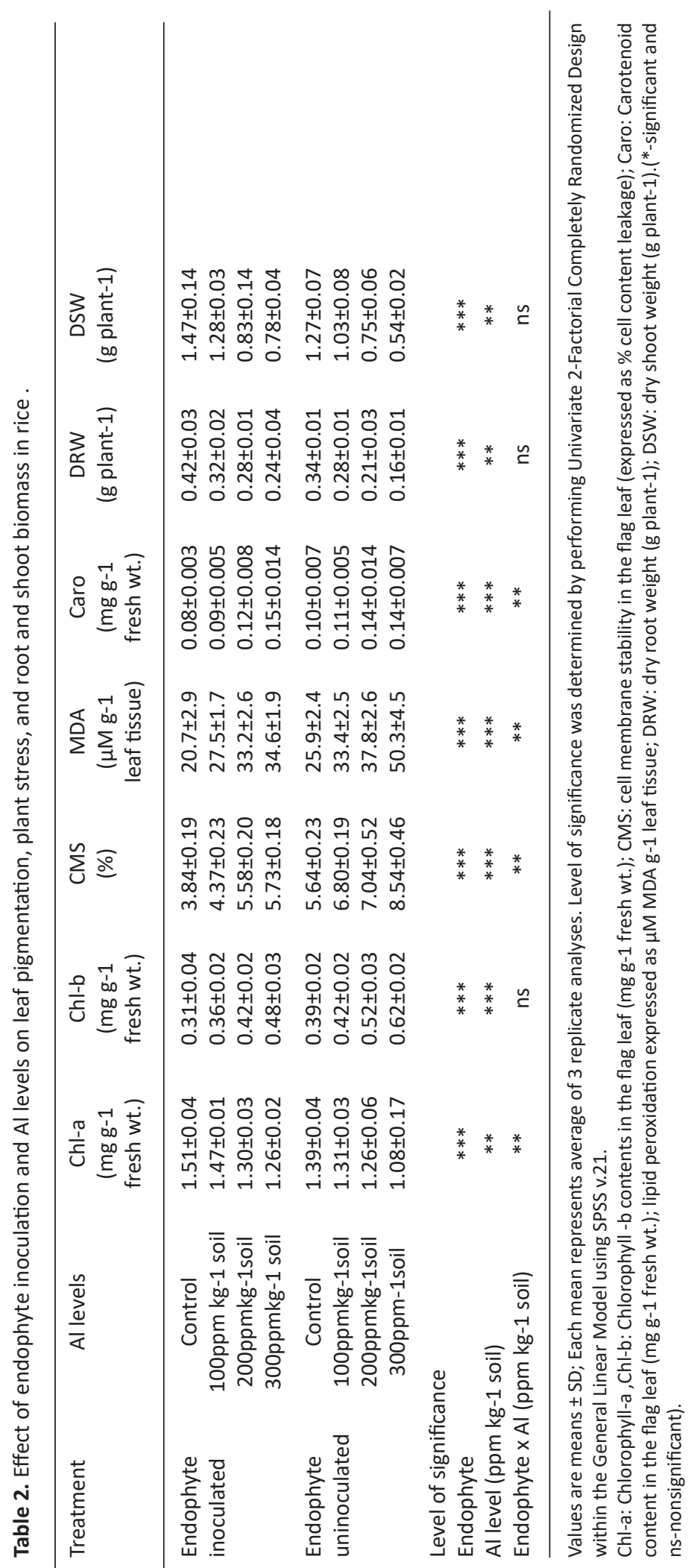




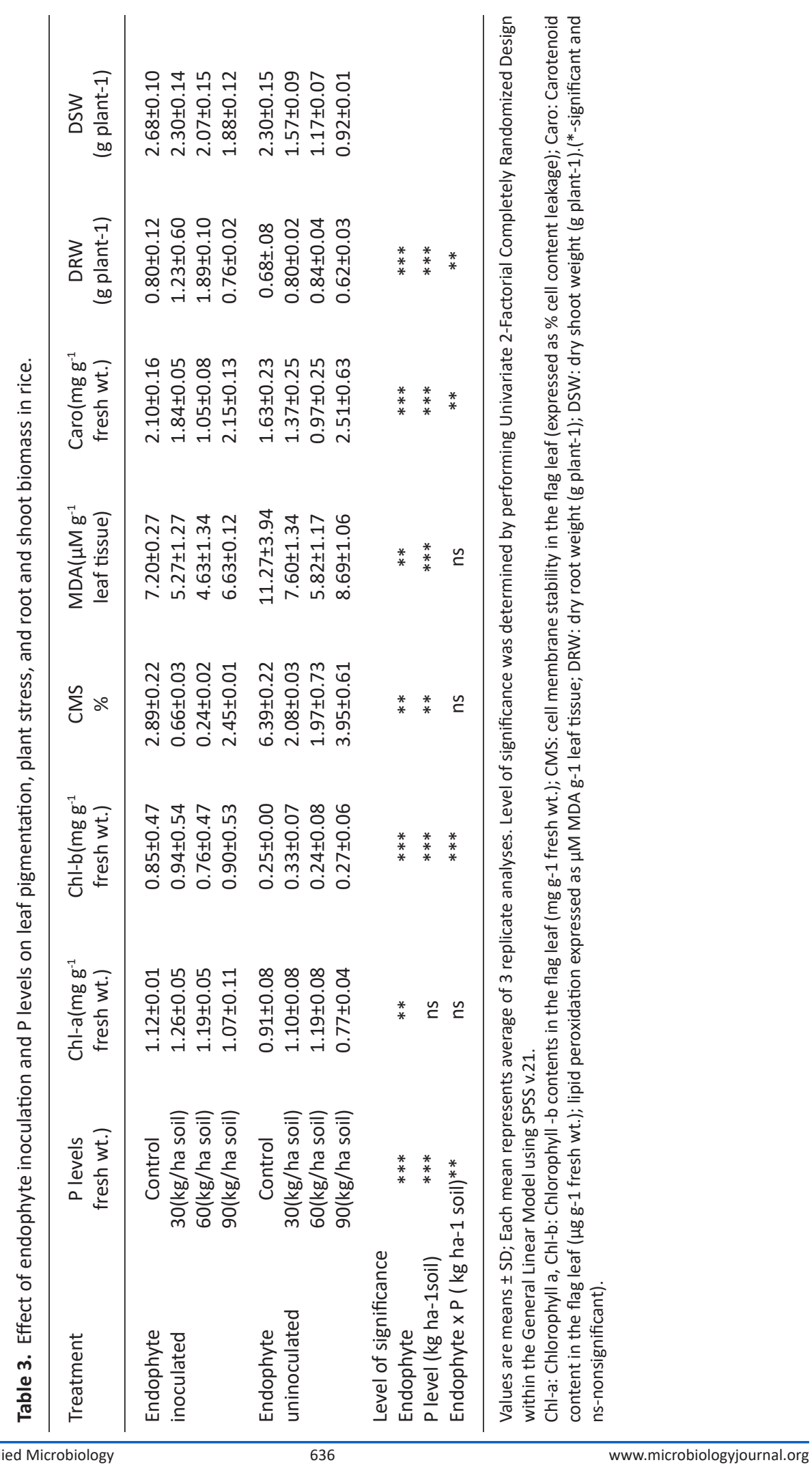


uninoculated plants (Table.3). The inoculated plants had significantly $(P<0.05)$ more chla content than uninoculated plants. However in the inoculated and uninoculated plants chlb and carotenoid content had no significant difference.

Both root and shoot dry weight had greater values in the inoculated plants than the uninoculated plants at low and moderate Al concentration and hence showed greater root and shoot biomass in control, 100ppm and 200 $\mathrm{pmm} \mathrm{kg}{ }^{-1}$ soil. The root growth reduced to a great extent with the increasing Al levels. Interestingly, the endophyte inoculated plants of $100 \mathrm{ppm} \mathrm{Al}$ $\mathrm{kg}^{-1}$ soil level and the uninoculated control plants produced comparable root biomass (Fig. 1 and Table 2).

The endophyte inoculated plants under different $\mathrm{P}$ doses showed significantly higher $(P<0.05)$ root and shoot biomass as evident from the dry root and shoot values shown in Table 2. The dry root and was highest among the plants grown under P-dose $60 \mathrm{~kg} / \mathrm{ha}$ soil followed by $30 \mathrm{~kg} /$ ha, control and $90 \mathrm{~kg} / \mathrm{ha}$ soil in both inoculated and uninoculated plants (Fig. 3 and Table 3 ) and shoot weight highest among the control in both inoculated and uninoculated plants (Table 3 )

This study clearly demonstrated that inoculation of efficient endophytes could exhibit fitness benefits to the host plant against Al toxicity as evident from improved root architecture, lowering stress impact (reduced CMS, MDA as well as $\mathrm{H}_{2} \mathrm{O}_{2}$ ) and incremental increase in shoot and root biomass in endophyte inoculated plants. Efficient endophyte could provide plant physiological advantage, growth and development under P-deficient acid soil as the rice plants grown in acidic soil under control having $P$ deficiency showed better root-shoot biomass, better root morphological features and lower stress indicator$\mathrm{CMS}$ values. The inoculated plants grown under increased $P$ dose $(30 \mathrm{~kg} / \mathrm{ha}, 60 \mathrm{~kg} / \mathrm{ha}, 90 \mathrm{~kg} /$ ha soil) also showed better physiological and growth parameters which indicates the efficiency of endophytes to improve growth parameters of plants along with fertilizer. It is found that the strain could dissolve insoluble inorganic phosphate, amended Pikovskaya's broth (pH 6.8)\} and organic phosphate $\mathrm{Na}$-phytate amended Pikovskaya's broth ( $\mathrm{pH} 4.6)$, produce indole-acetic- acid like substances, cellulose degrading activity and ACC deaminase activity which are widely recognized as plant growth promoting (PGP) mechanisms of beneficial microbes (Table 1). It has also been documented that IAA can help root and shoot development under stress conditions (Shi, 2004). Microbial phosphate solubilisation is a promising tool as biofertilizer as they mediate the solubilisation of inorganic phosphate and mineralization of organic phosphate which makes hosphorous available to the plants and enhance plant growth (Gaur et al., 1972). ACC is a well known plant growth promoting enzyme. This enzyme cleaves ACC, the immediate precursor of ethylene to ammonia and $\alpha$-ketobutyrate (Honma and Shimomura1978). As a result ethylene levels in plants are lowered which enhances plant growth as high ethylene levels in plants reduces their growth or can even cause plant death (Glick et al., 2007).

These possible PGP mechanisms probably helped the endophyte inoculated rice plants to support better root and shoot development, enhanced $\mathrm{P}$ uptake, and thereby reducing stress factors on the plant under Al toxic acid soil and even when $\mathrm{P}$ was added to the soil as fertilizer. Further, the root and shoot biomass data indicated that the toxic effect of an approximate 100ppm Al could be compensated due to endophyte inoculation.

\section{CONCLUSION}

The proposed results have shown that endophyte bacteria can help plants to have better growth in abiotic stress condition. So the study has shown the significance of exploration of new endophyte population and their beneficial effect on plants under abiotic stress condition. Results from the two sets of microcosm experiments on the pattern of root endophyte interactions across $\mathrm{Al}$ and $\mathrm{P}$ concentration gradients indicated that endophyte inoculation provide fitness benefits to rice crop against $\mathrm{Al}$ toxicity and also benefits the crop even in $\mathrm{P}$ deficient soil which is supplied with $P$ fertilizer.

\section{ACKNOWLEDGMENTS}

None. 


\section{CONFLICTS OF INTEREST}

The authors declare that there are no conflicts of interest.

\section{FUNDING}

This study was supported by the Department of Biotechnology, Ministry of Science and Technology, Govt. of India, New Delhi, India vide grant no. BT/PR15208/AGR/21/332/2011dtd. 02/07/2012.

\section{AUTHORS' CONTRIBUTIONS}

All authors listed have made a substantial, direct and intellectual contribution to the work and approved it for publication.

\section{DATA AVAILABILITY}

The dataset generated during the investigation are included in the manuscript.

\section{ETHICS STATEMENT}

This study does not contain any studies with human participants or animals performed by any of the authors.

\section{REFERENCES}

1. Adnan A, Mavinic DS and Kosh FA. Pilot-scale study of phosphorus recovery through struvite crystallization examining to process feasibility. Journal of Environmental Engineering and Science, 2018; 5(2): 315-324. https://doi.org/10.1139/s03-040

2. Armstrong GA and Hearst JE. Genetics and molecular biology of carotenoid pigment biosynthesis. FASEB J, 1996; 10: 228-237. https://doi.org/10.1096/ fasebj.10.2.8641556

3. Bajji M, Kinet J M and Lutts S. The use of the electrolyte leakage method for assessing cell membrane stability as a water stress tolerance test in durum wheat. Plant Growth Regulation, 2002; 36: 61-70. https://doi. org/10.1023/A:1014732714549

4. Bray RH and Kurtz LT. Determination of total, organic and available forms of phosphorus in soils. Soil Sci, 1987; 59: 39-45. https://doi.org/10.1097/00010694194501000-00006

5. Bulgarelli D, Schlaeppi K, Spaepen S, Ver Loren van Themaat E and Schulze-Lefert P. Structure and functions of the bacterial microbiota of plants. Anu. Rev. Plant Biol, 2013; 64: 807-38. https://doi. org/10.1146/annurev-arplant-050312-120106

6. Christensen TH, Zhang Z, Wei $Y$ and Collinge DB. Subcellular localization of $\mathrm{H}_{2} \mathrm{O}_{2}$ in plants. $\mathrm{H}_{2} \mathrm{O}_{2}$ accumulation in papillae and hypersensitive response during the barley-powdery mildew interaction. The Plant Journal, 1997; 11(6): 1187-1194. https://doi. org/10.1046/j.1365-313X.1997.11061187.x

7. Dey KK, Talukdar NC, Nongkhlaw FMW, Chung W-C,
Lo C-T and Young L-S. Isolation, characterization and practical significance of cellulose degrading bacteria from the gut wall of two ecologically distinct earthworms. Current Science, 2018; 114(7). https:// doi.org/10.18520/cs/v114/i07/1474-1484

8. Etminani $\mathrm{F}$ and Harighi B. Isolation and identification of endophytic bacteria with plant growth promoting activity and biocontrol potential from wild pistachio trees. Plant Pathol J, 2018; 34(3): 208-217.

9. Gaur AC and Ostwal KP. Influence of phosphate dissolving Bacilli on yield and phosphate uptake of wheat crop. Indian J Exp Biol, 1972; 10: 393-4.

10. Glick BR, Cheng Z, Czarny J, Duan J. Promotion of plant growth by ACC deaminase-containing soil bacteria. Eur. J. Plant Pathol, 2007; 119: 329-39. https://doi. org/10.1007/s10658-007-9162-4

11. Glick BR. Plant growth-promoting bacteria: Mechanisms and application. Scientifica, 2012; Article ID 963401. https://doi.org/10.6064/2012/963401

12. Guo TR, Yao PC, Zhang ZD, Wang JJ and Wang M. Involvement of antioxidative defense system in rice growing seedlings exposed to aluminum toxicity and phosphorus Deficiency. Rice Sci, 2012; 19(3): 207-212. https://doi.org/10.1016/S1672-6308(12)60042-0

13. Hardoim PR, Overbeek LS van, Berg G, Pirttila AM, Compant S, Campisano A, Doring $M$ and Sessitsch A. The hidden world within plants: Ecological and evolutionary considerations for defining functioning of microbial endophytes. Microbiol Mol Biol Rev, 2016. https://doi.org/10.1128/MMBR.00050-14

14. Hernandez I and Bosh SM. Linking phosphorus availability with photo-oxidative stress in plants. Journal of Experimental Botany, 2015; 66 (10): 2889-2900. https://doi.org/10.1093/jxb/erv056

15. Honma M, Shimomura T. Metabolism of 1-aminocyclopropane-1-carboxylic acid. Agric Biol Chem, 1978; 42: 1825-1831. https://doi.org/10.108 $0 / 00021369.1978 .10863261$

16. Jha B, Gontia I and Hartmann A. The roots of the halophyte Salicornia brachiata are a source of new halotolerant diazotrophic bacteria with plant growthpromoting potential. Plant Soil, 2012; doi 10.1007/s 11104-011-0877-9.

17. Kochian LV, Pineros MA and Hoekenga OA. The physiology, genetics and molecular biology of plant aluminum resistance and toxicity. Plant and Soil, 2005; 274: 175-195. https://doi.org/10.1007/s11104-0041158-7

18. Khare E, Mishra J and Arora NK. Multifaceted interactions between endophytes and plant: developments and prospects. Front. Microbiol, 2018; 9:2732. https://doi.org/10.3389/fmicb.2018.02732

19. Lane D. 16S/23S rRNA sequencing. In Nucleic Acid Techniques in Bacterial Systematic. Stackebrandt E, Goodfellow M, 1991; pp.115-175. Eds. John Wiley and Sons: New York, NY, USA, Brock TD.

20. Lynch JP and Brown KM. Topsoil foraging: An architectural adaptation of plants to low phosphorus availability. Plant and Soil, 2001; 237: 225-237. https:// doi.org/10.1023/A:1013324727040

21. Mandal SC. Introduction and historical overview. In: Mahapatra IC, Mandal SC, Misra C, Mitra GN, Panda 
N (eds). Acidic Soils of India, 1997; pp. 3-24. Eds. ICAR, New Delhi.

22. Mitter B, Brader G, Afzal M, Compant S, Naveed M, Trognitz $F$ and Sessitsch A. Advances in elucidating beneficial interations between plants, soil and bacteria. Advances in Agronomy, 2013; 121: 381-445. https://doi.org/10.1016/B978-0-12-407685-3.000074

23. Nayek $\mathrm{S}$, Choudhury $\mathrm{IH}$, Jaishee $\mathrm{N}$ and Roy $\mathrm{S}$. Specteophotometric analysis of chlorophylls and carotenoids from commonly grown fern species by using various extracting solvents. Res. J. Chem. Sci, 2014; 4(9): 63-69.

24. Panda SK, Baluska F and Matsumuto H. Aluminium stress signalling in plants. Plant Signalling and Behaviour, 2009; 4(7): 592-597. https://doi. org/10.4161/psb.4.7.8903

25. Penrose DM, Glick BR. Methods for isolating and characterizing ACC deaminase-containing plant growth-promoting rhizobacteria. Physiol Plant, 2003; 118: 10-15. https://doi.org/10.1034/j.13993054.2003.00086.x

26. Prashar P, Kapoor $\mathrm{N}$ and Sachdeva S. Rhizosphere: Its structure, bacterial diversity and significance. Rev Environ Sci Biotechnol, 2014; https://doi.org/10.1007/ s11157-013-9317-z

27. Prasad G, Euan JK, Natarajan M, Pallavolu RM, Barbara HR and Ladha JK. Endophytic colonization of rice by a diazotrophic strain of Serratia marcescens. J. Bacteriol, 2011; 183: 2634-2645. https://doi.org/10.1128/ JB.183.8.2634-2645.2001

28. Rahman MA, Lee SH, Ji HC, Kabir AH, Jones CS and Lee KW. Importance of mineral nutrition for mitigating aluminum toxicity in plants on acidic soils: Current status and opportunities. Int. J. Mol. Sci, 2018; 19(10): 3073. $h$ ttps://doi.org/10.3390/ijms19103073

29. Redman RS, Kim YO, Woodward CJDA, Greer C, Espino L, Doty S L and Rodriguez R J. Increased fitness of rice plants to abiotic stress via habitat adapted symbiosis: A strategy for mitigating impacts of climate change. Plos One, 2011; 6(7): e14823. https://doi.org/10.1371/ journal.pone.0014823

30. Roy A, Singh NU, Dkhar DS, Mohanty AK, Singh SB and Tripathy AK. Food security in North-East region of India -A state-wise analysis. Agricultural Economics Research Review, 2015; 28 (Conference Number): 259-266. https://doi.org/10.5958/09740279.2015.00041.5

31. Ryan RP, Germaine K, Franks A, Ryan DJ and Dowling DN. Bacterial endophytes: recent developments and applications. FEMS Microbiol. Lett, 2008; 278: 1-9. https://doi.org/10.1111/j.1574-6968.2007.00918.x

32. Sharma PFAB, Dubey RS and Pessarakli M. Reactive oxygen species, oxidative damage and antioxidative defence mechanism in plants under stressful conditions. Journal of Botany, 2012; https://doi. org/10.1155/2012/217037

33. Sharma UC and Singh RP. Acid soils of India: Their distribution, management and future strategies for higher productivity. Fertilizer News, 2002; 47(3): aluminiu growth

34. Stahl W and Sies H. Antioxidant activity of carotenoids. Molecular Aspects of Medicine, 2003; 24: 345-351. https://doi.org/10.1016/S0098-2997(03)00030-X

35. Shi GY. Effect of aluminium on growth and some physiological function of rice seedlings. Guihaia, 204; 24(1): 77-80.

36. Silva S. Aluminium toxicity targets in plants. Journal of Botany, 2012; https://doi.org/10.1155/2012/219462

37. Sullivan $\mathrm{CY}$ and Ross WM. Selecting for drought and heat resistance in grain sorghum. In: Mussell $\mathrm{H}$ and Staples RC, 1979; pp. 263-281. Eds. Stress Physiology in Crop Plants, John Wiley and Sons, New York.

38. Sultana S, Thakuria D and Handique PJ. Functional attributes and antagonism of root-associated bacteria of different rice cultivars from acid soil. Biological Engineering Research and Review, 2019; 6(2): 05-18

39. Thakuria D, Talukdar NC, Goswami C, Hazarika S, Boro $\mathrm{RC}$ and Khan MR. Characterization and screening of bacteria from rhizosphere of rice grown in acidic soils of Assam. Current Science, 2004; 86(7).

40. Thornton FC, Schaedle M and Raynal DL. Effect of aluminum on the growth of sugar maple in solution culture. Can. J. For. Res, 1986; 16: 892-896. https:// doi.org/10.1139/x86-159

41. Ticconi CA, Delatorre CA, Lahner B, Salt DE and Abel S. Arabidopsis $p d r 2$ reveals a phosphate-sensitive checkpoint in root development. The Plant Journal, 2004; 37: 801-81. https://doi.org/10.1111/j.1365313X.2004.02005.x

42. Verma SC, Ladha JK and Tripathi AK. Evaluation of plant growth promoting and colonization ability of endophytic diazotrophs from deep water rice. J. of Biotechnol, 2001; 91(2-3): 127-141. https://doi. org/10.1016/S0168-1656(01)00333-9

43. Wu D, Shen H, Yokawas K and Baluska. Alleviation of aluminium-induced cell rigidity by overexpression of OsPIN2 in rice roots. Journal of Experimental Botany, 2014; 65(18): 5305-5315. https://doi.org/10.1093/ jxb/eru292

44. Xu HX, Weng $X Y$ and Yang Y. Effect of phosphorus deficiency on the photosynthetic characteristics of rice plants. Russian Journal of Plant Physiology, 2007; 54: 741-748. https://doi.org/10.1134/ S1021443707060040

45. Yagi K. Lipid peroxides and human diseases. Chem. Phys. Lipids, 1987; 45: 337-351. https://doi. org/10.1016/0009-3084(87)90071-5

46. Yamamoto $\mathrm{Y}$, Kobayashi $\mathrm{Y}$ and Matsumoto $\mathrm{H}$. Lipid peroxidation is an early symptom triggered by aluminum, but not the primary cause of elongation inhibition in pea roots. Plant Physiol, 2001; 125(1):199208. https://doi.org/10.1104/pp.125.1.199

47. Zheng SJ and Yang JL. Target sites of aluminum phytotoxicity. Biologia Plantarum, 2005; 49(3): 321-331. https://doi.org/10.1007/s10535-005-0001-1 